\title{
Re-discussion and Correction of Shape Coefficient for Residential Buildings
}

\author{
Lingkun Jia ${ }^{1, *}$, Yiru Huang ${ }^{1}$, Zhietie Yue ${ }^{2}$, and Perry Pei-Ju Yang ${ }^{3,4}$ \\ ${ }^{1}$ College of Architecture and Urban Planning, Tongji University, Shanghai, China \\ ${ }^{2}$ Tongji Architectural Design (Group) Co., Ltd. Shanghai, China \\ ${ }^{3}$ Sino-U.S. Eco Urban Lab, College of Architecture, Georgia Institute of Technology, Atlanta, GA 30332, USA \\ ${ }^{4}$ Sino-U.S. Eco Urban Lab, College of Architecture and Urban Planning, Tongji University, Shanghai, China
}

\begin{abstract}
As one of the critical concepts in residential energy performance research field, shape coefficient has long been disputed for its validity of evaluating energy consumption. Although suggestions have been brought forward to try to optimize this concept, these proposals still have shortcomings and have not been tested. Based on analysing these existing optimizing proposals, this paper starts from prototype study and summarizes the problems of concept of shape coefficient in terms of definition and relationship with building energy. According to these current issues, the reason for negatively influencing the accuracy of shape coefficient with regard to assessing the building energy consumption is confirmed. By correcting the expression of shape coefficient through inserting a correction factor related to story height, corrected shape coefficient is proposed. Combined with built residential building samples, the corrected and original shape coefficient is contrasted at the macro statistical and micro experimental levels respectively. It is found that the new coefficient has closer correlation with residential building energy performance and is more accurate in evaluating the energy consumption.
\end{abstract}

\section{Introduction}

Residential buildings, which comprises more than $70 \%$ of land use in most cities and responsible for $70 \%$ of the energy consumption by buildings, significantly contributes to greenhouse gas emissions [1]. As up to 2 billion people will lack sufficient living space by 2025 , there is still a numerous number of residential buildings that need to be constructed [2]. Shape coefficient is the ratio of the external surface area of a building to its inclusive volume [3]. It not only characterizes the geometric features of a building, but also reflects the heat exchange efficiency between indoor and outdoor space to a certain extent. Ever since being mentioned by H. Lin for the first time in 1981 [4], shape coefficient has long been deemed as a key concept in residential building design and building energy related research. As a bridge to link architectural design and green building design, the study of shape coefficient is dedicated to both architects and engineers [5].

Any building of any type has its particular shape coefficient. The reason why this research focuses on shape coefficient for residential buildings is that, unlike public buildings, the similarity of residential buildings in design methods, functional composition and thermal performance, especially the sameness of the story height (around 2.8m) which is one of the key parameters in this paper, makes the research a practicable and widely applicable study.
Obviously, the larger shape coefficient is, the larger relative external surface area the building has, and then more heat will be lost or obtained through the building envelope. So, it is believed that the shape coefficient has a significant influence on building energy performance. A series of research methods such as sensitivity analysis [6] were taken into advantage to evaluate the effect of shape coefficient the energy use. The Energy-saving design standard for residential buildings (JGJ134-2010) states that a building will consume more energy by $2.4 \% \sim 3 \%$ when shape coefficient increases by 0.01 [7]. This kind of influence is independent of locations: with the same increment of shape coefficient, the annual relative variation rates (RVRs) of cooling and heating need are approximate regardless of the site of the buildings [8]. Some extreme cases are also taken into consideration to estimate the function of building shape in energy performance evaluation [9]. In addition, in order to improve the calculation efficiency, a new method to obtain the shape coefficient of residential buildings was presented based on Google Earth and GIS tools [10].

Except for the research on the influence from shape coefficient to building energy, the studies related to the relationship between sustainable buildings and the building shape were also conducted by more than 130 researchers [11]. From the perspective of Life Cycle Assessment (LCA), it is found that the shape of a building is more dominant to determine the embodied

\footnotetext{
${ }^{*}$ Corresponding author: lingkun.jia@gmail.com
} 
energy and embodied carbon per square meter than the building dimensions themselves such as wall thickness [12]. Meanwhile, in the design stage, the decision around the building shape has a great effect on building heating energy expenditure [13]. Besides energy demand, the building shape has strong impact on material resources of the buildings, too [14]. Solar heat gains are also simulated to assess the building shape in terms of thermal performance [15].

There is no doubt that the shape coefficient has a close connection with residential energy consumption. However, the validity and accuracy of the concept has not been universally acknowledged by academia. Experiments were performed to verify that although the increase of the story height of residential buildings would lead to the smaller shape coefficients, the consequent energy expenditure would rise at the same time [16-17], which was contradictory to most conclusions of the related research mentioned above.

It is undeniable that the concept of shape coefficient is imperfect. However, why such a coefficient with a barrage of questions is still considered to be a critical indicator related to residential energy consumption? Is the shape coefficient, even partly, reasonable? What is the problem with its relationship with residential energy performance? Facing the drawbacks, how to correct the shape coefficient drawbacks and can the corrected coefficient eventually achieve the purpose of optimizing the existing one? These questions are discussed in this paper.

\section{Literature review}

In order to clarify the object that the shape coefficient stands for, and link the building form with the energy performance in a logical way, suggestions have been provided by multiple researchers to perfect the concept of shape coefficient [18]. There are three main viewpoints among these papers.

\subsection{Regarding coefficient unit}

Given that shape coefficient is a variable which has a unit $(1 / \mathrm{m})$, some researchers insist that the unit itself may cause unpredictable mistakes and suggest that the expression of shape coefficient $(\mathrm{S}=\mathrm{F} / \mathrm{V})$ should be corrected [19]. Since the numerator, the external surface area of the building, and the denominator, the volume of the building, have different units, $\mathrm{m}^{2}$ and $\mathrm{m}^{3}$ respectively, which will lead to a phenomenon that the larger the building is, the smaller its shape coefficient is. To some extent, it is irrational to compare shape coefficients between buildings of different scales because their value ranges differ from each other. So, to make the concept of shape coefficient more reasonable, it is necessary to remove its unit by certain means.

In reality, what this viewpoint focuses on is not the key issue of shape coefficient. First, having a unit of measurement or not cannot be deemed as a criterion for judging whether a variable is reasonable. Many common coefficients such as heat storage coefficient have their units. Second, admittedly, after removing the unit, it is more convenient to compare shape coefficients between any buildings with any sizes without worrying about the value scopes. However, shape coefficient is brought forward to evaluate buildings' energy performance, rather than just being a sign of building shape. Whether the shape coefficient without a unit will affect its function of evaluating energy consumption has not been tested.

\subsection{Regarding building scale}

As there are two elements that influence shape coefficient: "Shape", which represents how irregular the building is, and "size", which indicates the dimensions of the building, some researchers consider that shape coefficient should be more specific and get rid of the impact of "size". Some of them think that the concept of shape coefficient needs to be redefined as "the ratio of the external surface area of a building to the bottom area of a cube which has the same inclusive volume with the building" [19]. Since the area of each face of a cube is equal, and a cube has the minimum surface area under a set volume (except sphere and other nonlinear shape), this new concept actually express the ratio of the external surface area of a building to the minimum external surface area which is able to enclose the building's volume.

As a matter of fact, this viewpoint is the derivative of the viewpoint of removing the unit. The new concept makes the shape coefficient not only a dimensionless variable, but comparable between buildings of different sizes. After correction, buildings have the equal shape coefficient as long as the building shapes are the same. However, as mentioned above, measuring the irregularity is not the final purpose of applying shape coefficient. If the new concept is just used to characterize the shape itself, and cannot be taken advantage to evaluate the energy consumption, it will lose its original meaning.

\subsection{Regarding evaluation basis}

Considering that the residential building energy is expressed as the electricity cost per $\mathrm{m}^{2}\left(\mathrm{kWh} / \mathrm{m}^{2}\right)$, but shape coefficient means the external building surface area per $\mathrm{m}^{3}\left(\mathrm{~m}^{2} / \mathrm{m}^{3}\right)$, some researchers hold the opinion that the difference between the measuring basis, say the denominators of fractions, is the main reason that why the energy consumption does not accurately correspond to shape coefficient. They suggest to replace shape coefficient by a new coefficient called "Building corresponding area coefficient" [20] or "Surface area coefficient" [21] which refers to the ratio of external surface area of a building to the total floor area. From this point of view, if building energy performance is assessed by electricity consumption for every square meter, the building shape should be judged by external surface area for every unit floor area, rather than every unit volume. Once again, this viewpoint realizes removing of the unit. 
Comparing the viewpoints mentioned above, this standpoint does not limit the research on building shape level, but emphasizes the relationship between shape coefficient and energy consumption. Nevertheless, it is still a partial view. As shape coefficient is a variable to bridge the building shape and energy consumption, it has dual meaning in terms of geometry and thermal physics. On the one hand, the substitute coefficient cannot be used to completely and precisely describe the shape of a building because floor area is an architectural concept and bears no direct relation to building shape. On the other hand, it is the building volume that determines how much heat the building needs, not the floor area. So, although the new coefficient, maybe, is more accurate in assessing the energy use, it is not as comprehensive as the original shape coefficient.

\section{Material and methods}

The paper carries out the research from two aspects: the prototype study and the case study. In the prototype study, the existing problems of current shape coefficient are summarized. On the basis of the findings, the concept of corrected shape coefficient is put forward. Subsequently, by taking advantage of hundreds of residential building examples, the case studies at the macro and micro levels are performed to test and verify the efficiency and accuracy of the new shape coefficient. In view of that shape coefficient is a parameter to represent the feature of the building shape, and the building envelope mainly influences the heat transfer efficiency, the energy simulated in this paper only consists of heating and cooling energy.

The residential building samples collected in this research are all located in Yangtze River Delta, so the weather data of Shanghai, the most developed city in this region where hundreds of residential buildings have been being constructed every year, was used in the simulation.

For simulation software, most experiments were performed in EnergyPlus for Archsim. The parameters were as follows:

As Yangtze River Delta is situated in the hot summer and cold winter climate zones, the values of indoor set temperature, Energy Efficiency Ratio (EER) and indoor heat loads which stands for the energy consumption of occupants, lighting, equipment, etc. were from Design Standard for Energy Efficiency of Residential Buildings in Hot Summer and Cold Winter Zones of China.

Table 1. Main energy simulation parameters.

\begin{tabular}{|c|c|c|}
\hline Item & $\begin{array}{c}\text { Winter } \\
\text { (Heating) }\end{array}$ & $\begin{array}{c}\text { Summer } \\
\text { (Cooling) }\end{array}$ \\
\hline $\begin{array}{c}\text { Indoor set } \\
\text { temperature }\end{array}$ & $18^{\circ} \mathrm{C}$ & $26^{\circ} \mathrm{C}$ \\
\hline $\begin{array}{c}\text { Energy Efficiency } \\
\text { Ratio (EER) }\end{array}$ & 1.9 & 2.3 \\
\hline $\begin{array}{c}\text { Indoor set heat } \\
\text { loads }\end{array}$ & $4.3 \mathrm{~W} / \mathrm{m}^{2}$ & $4.3 \mathrm{~W} / \mathrm{m}^{2}$ \\
\hline
\end{tabular}

The residential occupancy schedule was applied for heating and cooling simulation while all-time schedule for indoor heat loads.

The other thermal parameters and the building information such as heat transfer coefficient, window to wall ratio, structure and materials etc. will be set as the actual values of the building samples.

\section{Proposal of the new concept}

\subsection{Prototype pre-study}

The statement that the residential building will consume more energy as the shape coefficient rises is undependable. From prototype study by using basic thermal and geometric principles, it can be found that under some certain conditions, there is no positive correlation between shape coefficient and energy consumption, on the contrary, it even shows negative correlation between them.

Table 2. Information of prototype A.

\begin{tabular}{|c|c|c|c|c|}
\hline & A1 & A2 & A3 & A2 \\
\hline $\begin{array}{c}\text { Dimensio } \\
\text { ns }\end{array}$ & $3 \times 3 \times 3 \mathrm{~m}$ & $3 \times 3 \times 4 \mathrm{~m}$ & $3 \times 3 \times 5 \mathrm{~m}$ & $3 \times 3 \times 6 \mathrm{~m}$ \\
\hline $\begin{array}{l}\text { No. of } \\
\text { stories }\end{array}$ & 1 & 1 & 1 & 1 \\
\hline $\begin{array}{l}\text { Story } \\
\text { height }\end{array}$ & $3.0 \mathrm{~m}$ & $4.0 \mathrm{~m}$ & $5.0 \mathrm{~m}$ & $6.0 \mathrm{~m}$ \\
\hline
\end{tabular}

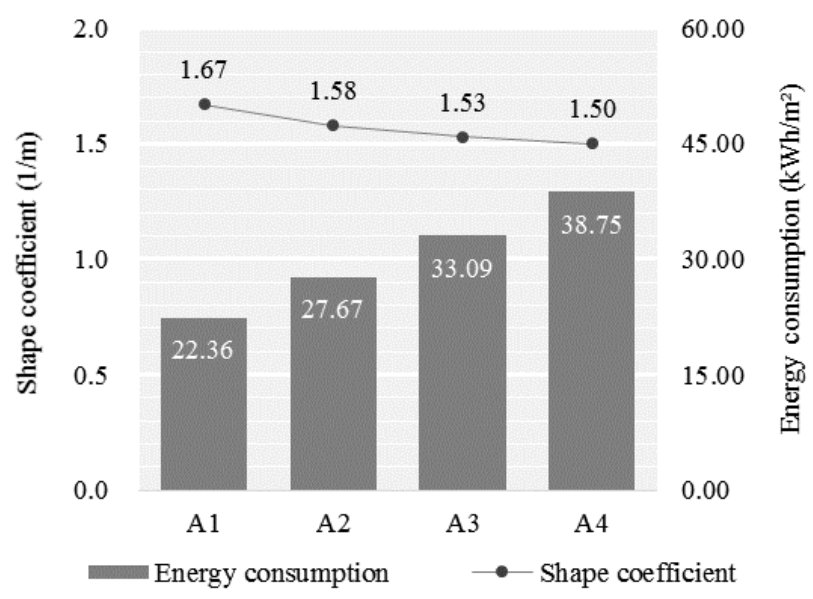

Fig. 1. Energy consumption of prototype A.

Prototype A: As Table 2 shows, four prototype residential buildings $\mathrm{A} 1, \mathrm{~A} 2, \mathrm{~A} 3$ and $\mathrm{A} 4$ have the base floors with the same shape and area. The only difference between them is story height, or total height since they 
are all single-story buildings. According to the expression of shape coefficient, S (Shape Coefficient) of the left building is always slightly larger than that of the next one to the right, say SA1 $>\mathrm{SA} 2>\mathrm{SA} 3>\mathrm{SA} 4$. However, the result of energy simulation (see Fig.1) shows that A1 is the most energy-efficient building. Furthermore, as the shape coefficient decreases from left to right, the energy consumption of the corresponding building rises constantly. This phenomenon is contrary to the conclusion that the larger the shape coefficient is, the lower the energy consumption is.

Table 3. Information of prototype B.

\begin{tabular}{|c|c|c|c|}
\hline B1 & B2 & B3 & B4 \\
\hline $3 \times 3 \times 12$ & $3 \times 3 \times 12$ & $3 \times 3 \times 12$ & $3 \times 3 \times 12$ \\
\hline 2 & 3 & 4 & 5 \\
\hline 6.0 & 4.0 & 3.0 & 2.4 \\
\hline
\end{tabular}

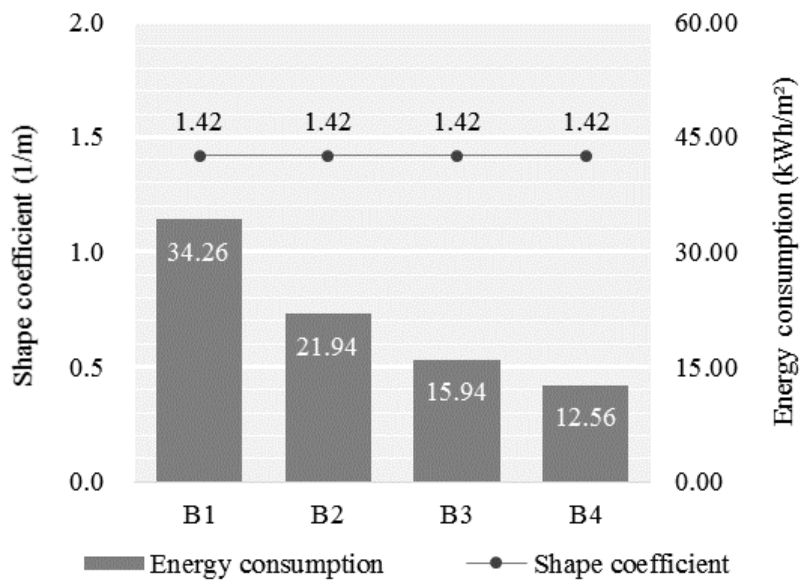

Fig. 2. Energy consumption of prototype B.

Prototype B: Table 3 shows the basic building information of prototype B1, B2, B3 and B4. The four residential buildings are almost the same except the total number of floors. As the number of stories increases from 2 to 5 , the story height becomes lower gradually from $6.0 \mathrm{~m}$ to $2.4 \mathrm{~m}$. As the outlines of these prototype buildings are the same, the shape coefficients of them are exactly identical. However, as Fig. 2 displays, the energy use of the four is distinctly different from each other. The more stories the building has, the less energy it consumes. Also, there is another noteworthy phenomenon that the total energy consumption per year of each building is similar (around 60-70 kWh). It means the inclusive volume of a building is the decisive factor to determine the total energy demand in the fixed thermal condition.

\subsection{Problems of current shape coefficient}

It can be concluded from the prototype pre-study that there is no strict positive correlation between shape coefficient and building energy consumption. The major reasons for this result can be analysed from two aspects.

From the aspect of the physical meaning of the shape coefficient, it is somewhat puzzling to distinguish "shape coefficient" from "shape". Admittedly, the more irregular the building shape is, the larger the shape coefficient of the building is, but conversely, when the shape coefficient becomes bigger, the building shape not necessarily becomes more uneven. As displayed in the prototype A, when a cube is stretched, the extent of its irregularity increases, but the shape coefficient decreases.

Apart from "shape", "size" is the other factor that influence shape coefficient. It can be found from the prototype study that "shape" and "size" not only cooperatively determine the shape coefficient, but impact the energy consumption together. In fact, the shape coefficient is just a manifestation of "shape" and "size". It is "shape" and "size", not shape coefficient, that ultimately bring about change on building energy performance. Consequently, if the irregularity of the building shape and the building size alter simultaneously and give rise to antagonism, it is possible that the shape coefficient negatively correlate with energy consumption.

From the perspective of relationship between shape coefficient and building energy performance, there exists ambiguity of the derivation process from the building shape to the energy consumption. As mentioned in 2.3, the shape coefficient indicates the external surface area of a building for every unit volume, while energy consumption is shown as the electricity for every unit floor area. Since the volume of a building neither directly relevant to the floor area nor derivable from it, it is defective to use shape coefficient as a measure without any acquisition to evaluate energy consumption. In other words, even if shape coefficient can be seen as a yardstick to assess the energy performance, the measuring objective should be electricity for every unit volume of the building.

\subsection{Deduction of corrected shape coefficient}

Before resolving the problems of the current shape coefficient, three principles should be stuck to. Firstly, the geometry characteristics of a residential building should be accurately described through shape coefficient. Secondly, the dual impact on residential energy consumption of the irregularity of the building shape and the building size should be taken into account at the same time. Lastly, when the shape coefficient changes, the trend of residential energy consumption should be 
consistent with the change direction of shape coefficient. The former two principles indicate that the basic structure of shape coefficient that the ratio of surface area to volume remain unchanged, and the third principle means necessary adjustments in the variables of the expression of shape coefficient is taken into place.

It is obvious from the prototype study that the reason why there exists inaccuracy of shape coefficient in evaluating energy consumption is that the current concept overlooks the impact of the inner geometry features of the building. The external geometry characteristic of a residential building, as the current shape coefficient expresses, determines the total energy demand. But when the number of stories of the building changes, the amount of energy for every floor or every unit floor area will become different, which will drive the residential energy consumption undergo a change even the shape coefficient stays the same. Under such circumstance, the positive correlation between shape coefficient and energy consumption does not exist any longer.

So, if a steady relationship between the building floor area and the shape coefficient can be established so as to make the shape coefficient reflect the variation of building floor area when the internal form of the building being redesigned, shape coefficient would be more faultlessly in predicting the tendency of residential energy consumption.

Following the analysis above, the concept of corrected shape coefficient is proposed and can be defined as the product of shape coefficient and modified story height factor. The modified story height factor refers to the ratio of the average story height of a residential building to the standard residential story height which is an artificial pre-set parameter. This value of this parameter is determined by residential design experience and does not affect the validity of the final result. In this paper, $3 \mathrm{~m}$ is applied as the standard residential story height. Therefore, the definition of corrected shape coefficient can also be given as: the equivalent value of the ratio of the external surface area of a building to its inclusive volume when the average story height is $2.8 \mathrm{~m}$. The expression is shown by Eq. (1).

$$
\begin{gathered}
S_{c}=c \cdot S=c \cdot F / V \\
c=h / h^{\prime}=h / 3
\end{gathered}
$$

In the expression, $\mathrm{S}_{\mathrm{c}}$ is corrected shape coefficient and $\mathrm{c}$ is modified story height factor which can be calculated by Eq. (2) where $h$ is average story height and $\mathrm{h}^{\prime}$ is standard residential story height.

Since modified story height factor is dimensionless $(\mathrm{m} / \mathrm{m})$, the unit of corrected shape coefficient remains $1 / \mathrm{m}$, the same as that of original shape coefficient.

\subsection{Comparison between original and corrected shape coefficients}

According to Equations, the corrected shape coefficients of prototype residential buildings A and B can be gained (see Figs.3 and 4).

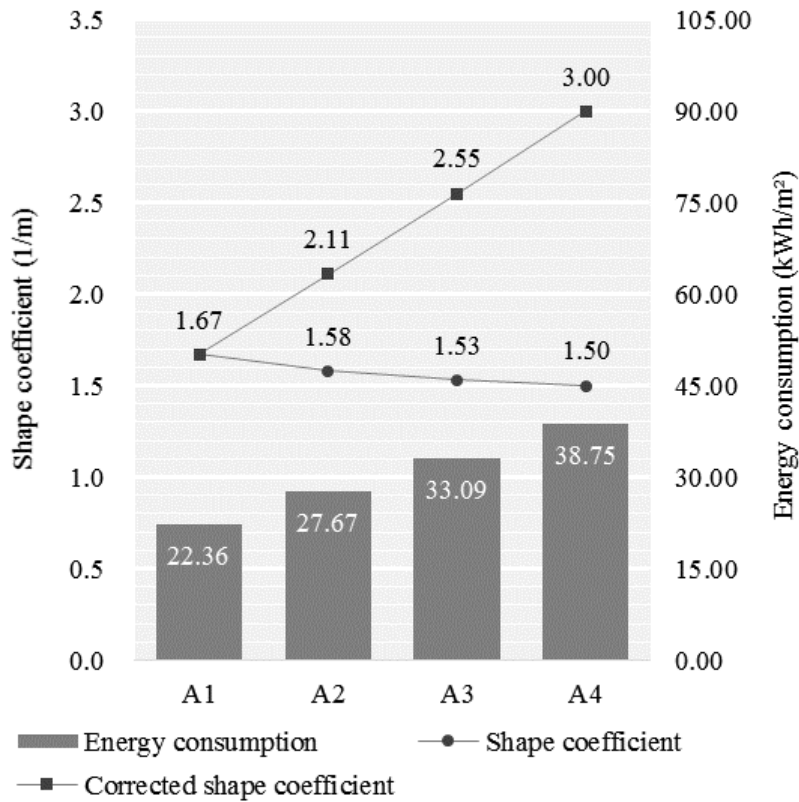

Fig. 3. Shape coefficient comparison of prototype A.

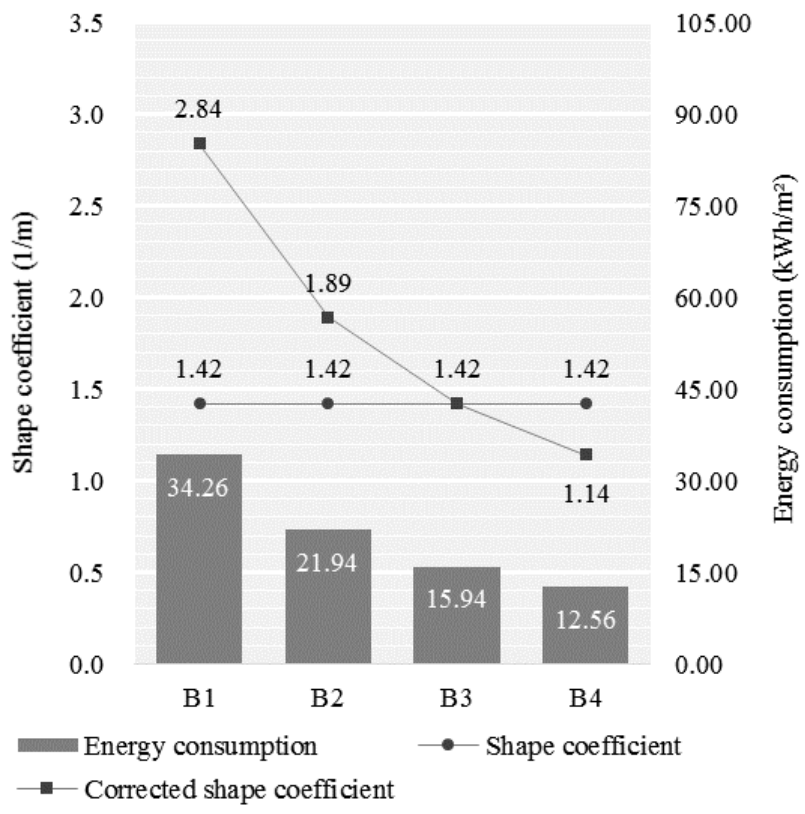

Fig. 4. Shape coefficient comparison of prototype B.

For prototype A, the values of original and corrected shape coefficients are completely different. As the building height rises from $3 \mathrm{~m}$ of $\mathrm{A} 1$ to $6 \mathrm{~m}$ of $\mathrm{A} 4$, the gap between the old and the new shape coefficients becomes increasingly bigger. Meanwhile, due to the increase of modified story height factor, there is a growing trend of corrected shape coefficient from 1.67 to 3.00 , which is opposite from the trend of original shape coefficient but in keeping with the tendency of energy consumption.

Similarly, when it comes to prototype B, the corrected shape coefficient of each residential building differs from its original counterpart. Although the shape coefficients of the building prototypes are all 1.42 for the 
external geometry characteristics keep the same, as the number of stories increases, the internal geometry structure undergoes a change which result in a continuously fall of the value of corrected shape coefficient and in the same trend of energy consumption.

To sum up, differently from original shape coefficient, the corrected shape coefficient can not only signify whether there is a change of the internal space layout, and also evaluate the trend of energy consumption more accurately and sensitively.

\section{Case study and discussion}

\subsection{Statistical research}

If corrected shape coefficient is more effective at evaluating residential energy performance, the two should have a relative high correlation. In order to verify this conjecture, 154 built residential building samples are collected from Yangtze River Delta which is in the hot summer and cold winter climate zone of China. All of these buildings were involved in energy simulation before entering construction so the simulated energy results are ready. Original and corrected shape coefficient can be calculated by obtaining the geometry data of the buildings.

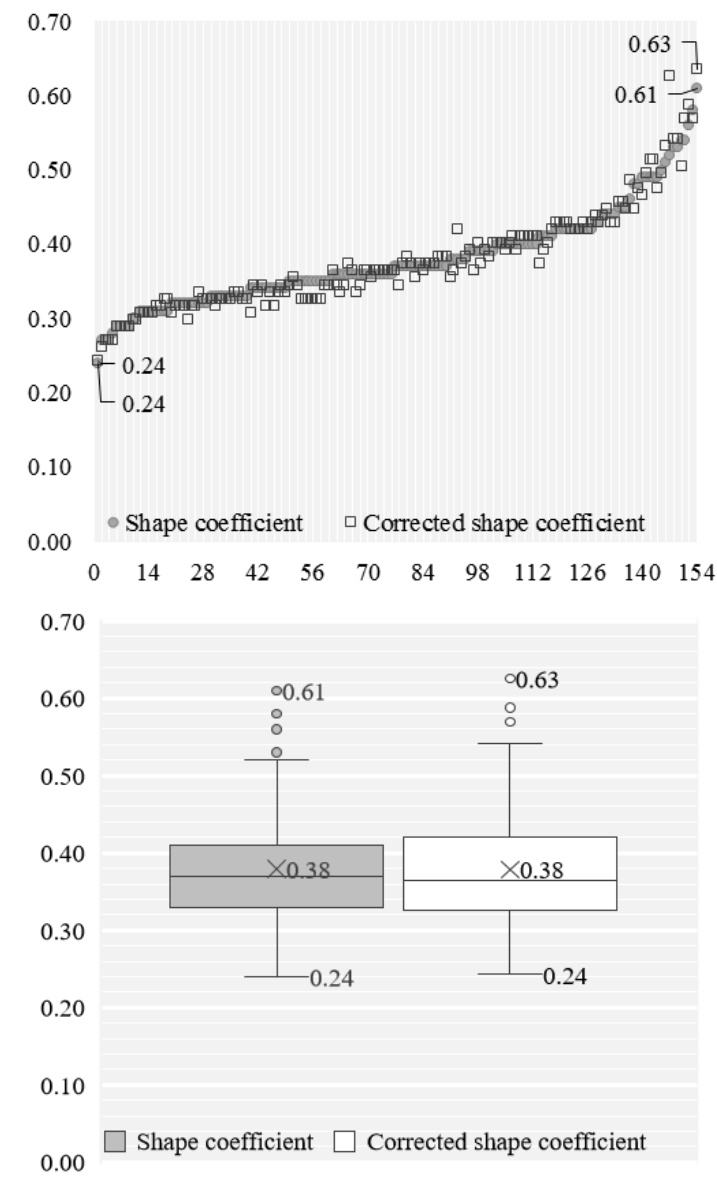

Fig. 5. Shape coefficients of 154 building samples.

As Fig.5 illustrates, the building samples whose original shape coefficients range from 0.24 to 0.61 while their corrected counterparts from 0.24 to 0.63 cover the most forms of the current built residential buildings in this region. Also, three phenomena can be observed from the graph. First, the tendency of the two coefficients are almost identical as the rise of original shape coefficient is matched by parallel trend of the corrected one. Second, the corrected shape coefficients are extremely similar with the original ones. Except for individual samples, the difference between the two coefficients of most samples is within 0.02 , which accounts for $5 \%$ of the average value of the shape coefficients. This phenomenon suggests that, on the hand, the story height of the built residential buildings is generally close to $3 \mathrm{~m}$, and on the other hand, the contemporary residential buildings have considerable similarity in terms of internal space design. Last but not least, the distribution of the scattered dots of the corrected shape coefficient are more discrete than the dots of original coefficient, which implies that the corrected shape coefficient is a more sensitive variable in exactly expressing the characteristics of the shape of a residential building.

The correlation analysis (see Table 4) proves, again, the closer relationship between corrected shape coefficient and energy expenditure. Although the gap between original shape coefficient and corrected shape coefficient is so tiny that the Pearson correlation coefficient is close to $1(0.980)$ which implies a nearly perfect linear positive correlation, the relationship between the two shape coefficients and energy consumption are quite unlike that the correlation coefficient between corrected shape coefficient and energy consumption (0.612) is much higher than the corresponding figure (0.548) of its original counterpart.

As a result, statistically, corrected shape coefficient realizes its purpose of optimizing the original shape coefficient and is more efficient in assessing the residential energy use level.

Table 4. Correlations between original/corrected shape coefficient and energy consumption.

\begin{tabular}{|c|c|c|c|}
\hline $\mathbf{S}$ & 1 & \multicolumn{2}{l}{} \\
\hline $\mathbf{S c}$ & $.980^{* *}$ & 1 & \\
\hline $\mathbf{E}$ & $.548^{* *}$ & $.612^{* *}$ & 1 \\
\hline $\begin{array}{c}\text { Pearson } \\
\text { Correlation }\end{array}$ & $\mathbf{S}$ & $\mathbf{S c}$ & $\mathbf{E}$ \\
\hline **. Corretation & &
\end{tabular}

**. Correlation is significant at the 0.01 level (2-tailed).

\subsection{Experimental research}

Taking a typical sample from the 154 residential buildings as an example, the validity of corrected shape coefficient can be tested.

The selected building sample is located in Shanghai, the basic thermal parameters can be seen in table 5 . The research modified the building sample by adjusting the story height or the number of stories to evaluate the energy performance. Unlike the previous prototype study, 
the adjustment is restricted in some amount to guarantee the value of residential story height is within a reasonable and common range. Specifically, on the basis of the original building case which is as the baseline, four building remodelling methods were applied (see Table 6):

(1) Increase the story height by $0.1 \mathrm{~m}(\mathrm{H}+)$;

(2) Decrease the story height by $0.1 \mathrm{~m}(\mathrm{H}-)$;

(3) Add another floor without changing the total building height $(\mathrm{S}+)$;

(4) Remove one floor without changing the total building height (S-).

It is notable that shape coefficient is greatly influenced by the building scale. The larger the building is, the smaller its shape coefficient is. In this section, the size of the building sample is so considerable that the change of the building shape which is caused by the alteration of the story height or the number of stories is too subtle to be displayed by the commonly used shape coefficient which is accurate to two decimal places. So, as listed in diagrams, shape coefficients are all rounded to three decimal places instead.

Table 5. Thermal parameters of the building sample.

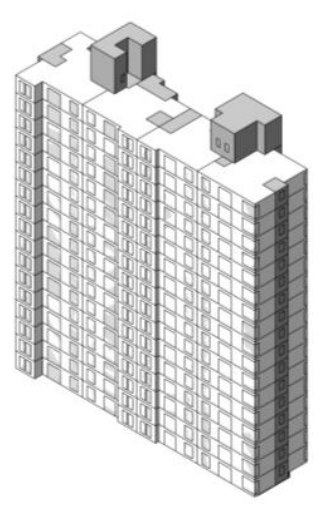

\begin{tabular}{|c|c|}
\hline \multicolumn{2}{|c|}{$\begin{array}{l}\text { Heat transfer coefficient } \\
\qquad\left(\mathrm{W} /\left(\mathrm{m}^{2} \cdot \mathrm{K}\right)\right)\end{array}$} \\
\hline Roof & 0.92 \\
\hline Façade & 1.11 \\
\hline Partition & 2.62 \\
\hline Window & 3.20 \\
\hline Floor & 2.92 \\
\hline \multicolumn{2}{|c|}{ Window to wall ratio } \\
\hline East & 0.06 \\
\hline West & 0.05 \\
\hline South & 0.37 \\
\hline North & 0.27 \\
\hline
\end{tabular}

Table 6. Building information of baseline case and variations.

\begin{tabular}{|c|c|c|c|c|c|}
\hline & B & H+ & H- & S+ & S- \\
\hline $\mathrm{S}(1 / \mathrm{m})$ & 0.309 & 0.307 & 0.310 & 0.309 & 0.309 \\
\hline $\mathrm{Sc}(1 / \mathrm{m})$ & 0.319 & 0.329 & 0.310 & 0.302 & 0.340 \\
\hline $\begin{array}{c}\text { No. of } \\
\text { stories }\end{array}$ & 18 & 18 & 18 & 19 & 17 \\
\hline $\begin{array}{c}\text { Story height } \\
(\mathrm{m})\end{array}$ & 2.90 & 3.00 & 2.80 & 2.74 & 3.08 \\
\hline $\begin{array}{c}\text { Floor area } \\
\left(\mathrm{m}^{2}\right)\end{array}$ & 8480 & 8480 & 8480 & 8966 & 7994 \\
\hline
\end{tabular}

In Fig. 6, as the story height or number of stories changes, the corrected shape coefficient is much more sensitive to the modification of inner layout of the building than its corrected counterpart. As expected, the fluctuation of energy consumption of the residential building models were in tune with the trend of corrected shape coefficient from beginning to end no matter how the original shape coefficient changes. In addition, it is can be found that in any two cases, the building with larger corrected shape coefficient always consumes more energy. This suggests that the corrected shape coefficient is not only highly correlated with energy consumption, but also has very high precision in evaluating it.

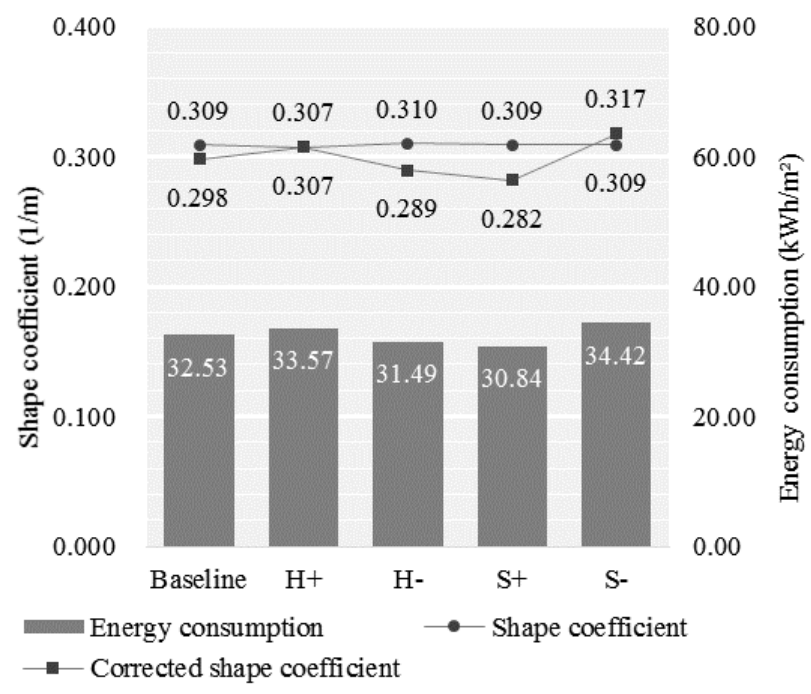

Fig. 6. Comparison between variations of building sample.

\subsection{Disadvantage of corrected shape coefficient}

The improvements of the new shape coefficient has been manifested from variouRs perspectives in the paper, however, there are still two shortcomings that need to be tackled. First, although the calculation technique is not complicated, compared to the old concept, more building information, i.e. the story height, has to be collected. Second, it is somewhat difficult to obtain the corrected shape coefficient when the inner space of the residential building is not regular. For example, the design of loft, mezzanine, duplex, split-level building would bring various story height which will adversely affect the calculation of the corrected shape coefficient.

These shortcomings mainly have the negative impact on the convenience of calculation. Fortunately, with the availability of building information under the context of big data and the development of the parametric design tools, the disadvantages will be gradually overcome.

\section{Conclusion}

Starting from analysing the dispute over the current concept of shape coefficient, this paper proposes corrected shape coefficient by inserting a new parameter called modified story height factor into the expression of original shape coefficient based on thermal and geometric principles. Then, the values of the new and the old shape coefficients, as well as their relationship with the residential building shape and energy consumption are simulated, compared and discussed from the angles of prototype study and case study. As opposed to the existing optimization suggestions, the corrected shape coefficient proposed in this research does not completely deny the original shape coefficient, instead, it retaining 
the reasonable part of the original concept while optimizing it. The advantages of the corrected shape coefficient are mainly demonstrated in the following four aspects.

(1) This paper clarifies the misunderstanding of original shape coefficient and recognizes the necessity of its unit which remains unchanged in the corrected shape coefficient. It is also believed that the shape coefficient, no matter the new or the old, should represents both the irregularity of the building shape and the building scale, for either of them is related to energy performance.

(2) For the reason that the fact that the energy consumption per unit is impacted by the inner space form is proved, corrected shape coefficient is more comprehensive for expressing the building shape. Apart from the external geometry features, the characteristics of the internal layout of the residential building can also be reflected in the corrected shape coefficient.

(3) With the including of the modified story height factor, the confusing phenomenon that the energy consumption drops as the shape coefficient increases because of the changing of story height is eliminated. Thus, corrected shape coefficient is more capable to evaluate the energy expenditure of residential buildings.

(4) The energy performance is more sensitive to the corrected shape coefficient in terms of trend and values. At the macro level, they have a relative higher positive correlation while at the micro level, even a marginal change of corrected shape coefficient can lead to a fluctuation of energy consumption.

Due to the addition of an extra variable in the expression, the calculation process of corrected shape coefficient is not as convenient as that of original one. Nevertheless, the problem will be finally addressed as the development of calculation tools. In conclusion, thanks to higher accuracy and efficiency, corrected shape coefficient has a promising prospect in the field of energy-saving residential building design and research of the relationship between residential form and energy performance.

\section{Acknowledgement}

This research is funded by National Natural Science Foundation of China (51478315) and National Key R\&D Program of China (No.2016YFC0700200).

\section{References}

1. I. Y. choi, S. J. Cho, J. T. Kim. Energ Buildings 46, 123-131 (2012)

2. UN-Habitat, Urbanization And Development (2016) http://wcr.unhabitat.org/wpcontent/uploads/2017/02/WCR-2016-FullReport.pdf

3. China Academy of Building Research. JGJ 26-2018, Design standard for energy efficiency of residential buildings in severe cold and cold zones (China Architecture \& Building Press, 2018)

4. H. Lin. Archit J 06, 37-41+3 (1981)
5. P. Depecker, C. Menezo, J. Virgone, S. Lepers. Build Environ 36, 627-635 (2001)

6. T. L. Hemsath, K. A. Bandhosseini. Renew Energ 76, 526-538 (2015)

7. China Academy of Building Research. JGJ1342010, Design standard for energy efficiency of residential buildings in hot summer and cold winter zones. (China Architecture \& Building Press. 2010)

8. L. Enshen. Build Environ 40, 473-480 (2005)

9. S. C. Zerefos, C. A. Tessas, A. M. Kotsiopoulos, D. Founda, A. Kokkini. Energ Buildings 48, 97-102 (2012)

10. F. Qi, Y. Wang. Energ Buildings 76, 72-80 (2014)

11. Y. Huang, L. Jia. Housing Sci 35, 5-10 (2015)

12. M. Lotteau, P. Loubet, G. Sonnemann. Energ Buildings 154, 1-11 (2017)

13. E. Bostancioğlu. Archit Sci Rev 53, 441-467 (2010)

14. J. Parasonis, A. Keizikas, D. Kalibatiene. Archit Eng Des Manage 8, 246-256 (2012)

15. E. Yasa, V. Ok. Energ Buildings 73, 192-199 (2014)

16. J. Hong, Z. Peng, L. J Chengdu Univ 02, 148-150 (2008)

17. W. Lu, D. Bin, H. Weijun. J Jinling Inst Tech 25, 22-24 (2009)

18. D. Lixing, L. Yueming, B. Jinsong. Archit Constr 12, 19-22 (2003)

19. H. Wei. Build Energ Efficien 05, 19-21 (2008)

20. Z. Peng. H. Weijun. Sichuan Build Sci 38, 297-300 (2012)

21. L. Bing, H. Lingjiang. Build Energ Efficien 41, 55$57+65(2013)$ 